\title{
DEFINISI HAK PATEN DAN PENERAPAN PATEN PADA STUDY KASUS SAMSUNG MOBILE
}

\author{
ALVINA DAMAYANTI \\ 155100004, 785567844 \\ Fakultas Komputer \\ Alvinadamayanti.student@umitra.ac.id
}

\begin{abstract}
Definisi paten merupkaan suatu hak khusus yang diberikan oleh suatu negara kepada seorang penemu atau pencipta atas suatu hasil pencapaian atau hasil ciptaan dari penemu itu sendiri yang salahsatunya dibidang teknologi. Hak paten tersebut diatur dalam Pasal 1 Ayat 1 UU mengenai HAK PATEN. Kata paten, berasal dari bahasa inggris patent, yang awalnya berasal dari kata patere yang berarti membuka diri (untuk pemeriksaan publik), dan juga berasal dari istilah letters patent, yaitu surat keputusan yang dikeluarkan kerajaan yang memberikan hak eksklusif kepada individu dan pelaku bisnis tertentu. Dari definisi kata paten itu sendiri, konsep paten mendorong inventor untuk membuka pengetahuan demi kemajuan masyarakat dan sebagai gantinya, inventor mendapat hak eksklusif selama periode tertentu. Mengingat pemberian paten tidak mengatur siapa yang harus melakukan invensi yang dipatenkan, sistem paten tidak dianggap sebagai hak monopoli.

Artikel kali ini akan membahas mengenai sebuah judul yaitu "DEFINISI HAK PATEN DAN PENERAPAN PATEN PADA STUDY KASUS SAMSUNG MOBILE". Samsung mobile, samsung mobile merupakan sebuah perusahaan terkenal yang ada du dunia. Siapa yang tidak mengenal produk yang satu ini. berbicara mengenai kebesaran nama dari sebuah produk teknologi yang satu ini, tidak terlepas dari sebuah kerja keras seseorang yang membuat, menghasilkan, menciptakan produk ini hingga menjadi besar seperti sekarang. Nama itu adalah LEE BYUNG CHULL, mendirikan paten pada tangga 1 Maret 1938 di Daegu, Korea Selatan. Dengan itu, penerapan HAK PATEN secara eksklusif dipegang oleh LEE BYUNG CHULL sebagai pendiri dari produk tersebut.

Dengan demikian, dengan definisi dan fakta diatas dapat kita simpulkan bahwa sesuatu yang besar, sesuatu yang luar biasa, sesuatu yang dihargai dan patut diperhitungkan memang tak luput dari peran seseorang atau beberapa orang yang menjadi pemegang paten dari sebuah produk dan tentunya memang diperlukannya suatu keinginan dan npemikiran yang besar pula untuk menuju sesuatu yang besar dan luar biasa.
\end{abstract}

Kata Kunci : patent, publik, letters, eksklusif, inventor. 


\section{A. INTRODUCTION}

Hak Paten adalah suatu hak khusus yang diberikan oleh suatu negara kepada seorang penemu atau pencipta atas suatu hasil pencapaian atau hasil ciptaan dari penemu itu sendiri yang salahsatunya dibidang teknologi. Hak paten tersebut diatur dalam Pasal 1 Ayat 1 UU mengenai HAK PATEN. Kata paten, berasal dari bahasa inggris patent, yang awalnya berasal dari kata patere yang berarti membuka diri (untuk pemeriksaan publik), dan juga berasal dari istilah letters patent, yaitu surat keputusan yang dikeluarkan kerajaan yang memberikan hak eksklusif kepada individu dan pelaku bisnis tertentu. Dari definisi kata paten itu sendiri, konsep paten mendorong inventor untuk membuka pengetahuan demi kemajuan masyarakat dan sebagai gantinya, inventor mendapat hak eksklusif selama periode tertentu. Mengingat pemberian paten tidak mengatur siapa yang harus melakukan invensi yang dipatenkan, sistem paten tidak dianggap sebagai hak monopoli.

Sesuai dengan judul artikel yang saya tulis ini tentu saja tidak terlepas dari hal-hal yang menyangkut mengenai kepemilikan atau kepatenan dari produk tersebut.

Berikut ini adalah sedikit potret mengenai kepemilikan paten dari sebuah produk yaitu Samsung Mobile :

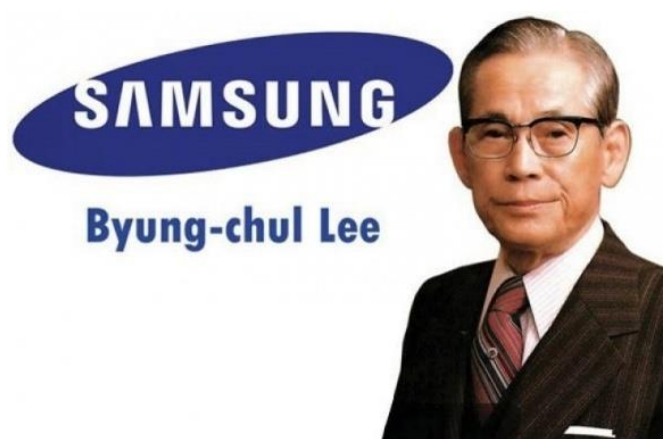

- Nama : Lee Byung Chull

- Lahir : 12 Februari 1910

- tempat lahir dan menetap : Uiryeong County, Korea Selatan

- Meninggal : 19 November 1987, Seoul, Korea Selatan.

- Kebangsaan : Korea Selatan

- Pendidikan : Universitas Wesada (Tidak sampai lulus).

- Anak-anak : Lee Kun-hee, Lee Maeng-hee, Lee MyungHee, dan lainnya.

- Cucu : Lee Jae-yong, Lee Boojin, Lee Yoon-hyung, Lee Seohyun, dan lainnya.

Saat ini, perusahaan ini sudah beroperasi di lebih kurang 58 negara di dunia dan sudah memiliki lebih dari 210.000 pekerja yang tersebar di berbagai penjuru belahan dunia. Hingga pada tahun 2018, SAMSUNG sudah menjadi salah satu merk terbesar dan terpercaya di kalangan teknologi dan mampu mengeluarkan produk yang mampu bersaing pada dunia teknologi yang semakin hari semakin canggih ini. 
Sekarang ini, Samsung sudah beroperasi dalam 6 sektor bisnis, yaitu :

a. Telephone genggam dan peralatan telekomunikasi lainnya.

b. Peralatan rumah tangga digital (termasuk mesin cuci, oven gelombang mikro, kulkas, pemutar DVD, dll),

c. Media digital seperti LCD.

d. Peralatan seperti laptop, PC, printer, dll.

e. Peralatan kendaraan bermotor (termasuk alat berat).

f. Peralatan pendukung teknologi seperti powerbank, printer, dll.

Sedikit mengenal sejarah tentang usaha di bidang teknologi dari pemilik paten samsung yaitu LEE BYUNG CHULL. Saat ini, siapa yang tidak mengenal Samsung? Yaitu perusahaan produsen alat elektronik seperti smartphone, laptop, notebook, dll yang cukup besar di dunia. Meskupun begitu, siapa yang menyangka bahwa pada awalnya seorang LEE BYUNG CHULL mengawali usahanya dengan berjualan buah, sayur dan ikan kering di Taegu, timur laut Korea.

Pada tahun 1937, akibat pecahnya perang antara Cina dengan Jepang, Byung-chul, yang saat itu sesungguhnya telah memiliki bisnis kecil penggilingan padi dan transportasi di Masan, pantai

tenggara semenanjung Korea, terpaksa memindahkan bisnisnya ke Taegu. Dari sanalah legenda Samsung dimulai.

Setelah bertahun tahun terlewati, yang begitupun LEE BYUNG CHULL mengalami jatuh bangun proses bisnis nya. Namun ia tetap bersikeras dan membulatkan tekat agar bisa menjadikan apa yang sudah diciptakannya menjadi sesuatu yang besar.

\section{B. CONTENT STUDY REFERENSI}

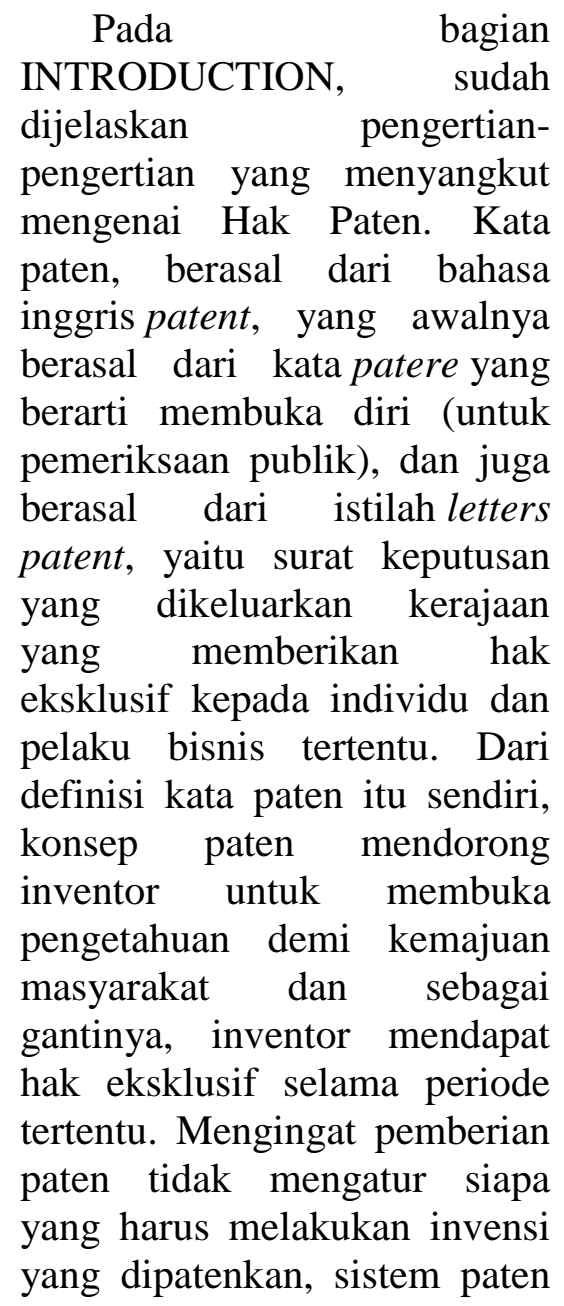


tidak dianggap sebagai hak monopoli.

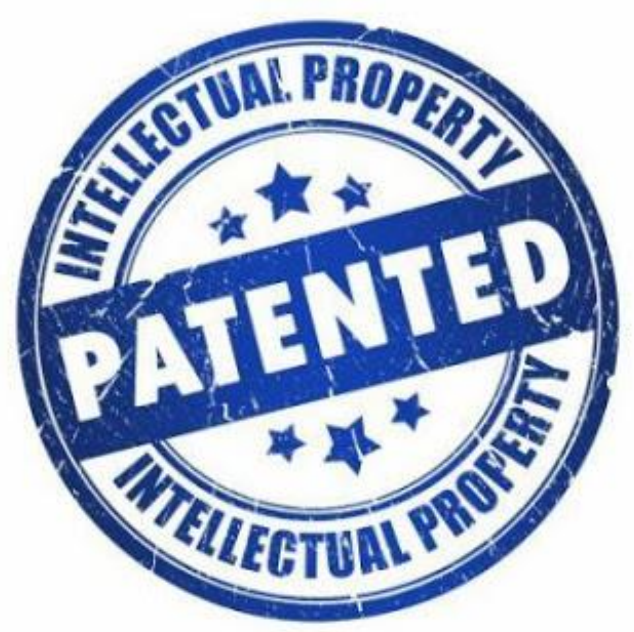

Seperti sudah dijelaskan pada INTROCTION, bahwa pemegang hak paten dari produk samsung ini adalah seorang yang berkebangsaan Korea Selatan bernama LEE BYUNG CHULL. Banyak jenis teknologi yang sudah dipatenkan oleh LEE BYUNG CHULL hingga saat ini.

Namun, dalam pelaksanaan bisnisnya, banyak perjalanan yang harus dilalui oleh LEE BYUNG CHULL serta team demi tercapainya sesuatu yang spektakuler hingga saat ini.

Berikut adalah aturan-aturan mengenai paten :

Hak Paten Indonesia saat ini diatur dalam UU No. 13 tahun 2016. UU paten ini merupakan UU terbaru yang menggantikan UU paten No. 14 Tahun 2001 karena banyaknya substansi yang perlu ditambahkan maupun diperbaiki.

Berdasarkan penuturan dari Kepala Bagian Hukum, Biro
Hukum, Kerjasama dan Humas BPPT, substansi dalam UU No 13 tahun 2016 ini lebih dari 50 persen berubah. Dengan adanya UU paten yang baru ini juga bertujuan agar para peneliti semakin memahami tata cara pengajuan paten dan membuat invensi akan semakin bertambah. UU paten ini juga sudah menyesuaikan dengan ketentuan peraturan internasional.

UNDANG - UNDANG (UU) PATEN REPUBLIK INDONESIA :

- UU Nomor 13 Tahun 2016 tentang Paten

- UU Nomor 14 Tahun 2001 tentang Paten

- Penjelasan UU Nomor 14 Tahun 2001 tentang Paten

PERATURAN PEMERINTAH (PP) BIDANG PATEN

- Peraturan Pemerintah Republik Indonesia Nomor 27 Tahun 2004 tentang Tata Cara Pelaksanaan Paten oleh Pemerintah ditetapkan Tanggal 5 Oktober 2004.

- Peraturan pemerintah ditetapkan Tanggal 5 Oktober 2004

- Peraturan Pemerintah Republik Indonesia Nomor 31 Tahun 1995 tentang Komisi Banding Paten ditetapkan Tanggal 29 Agustus 1995.

- Peraturan Pemerintah Republik Indonesia Nomor 
11 Tahun 1993 tentang Bentuk dan Isi Surat Paten ditetapkan Tanggal 22 Februari 1993.

- Peraturan Pemerintah Republik Indonesia Nomor 33 Tahun 1991 tentang Pendaftaran Khusus Konsultan Paten ditetapkan Tanggal 11 Juni 1991.

- Peraturan Pemerintah Republik Indonesia Nomor 45 Tahun 2016 tentang Jenis Dan Tarif Atas Penerimaan Negara Bukan Pajak Yang Berlaku Pada Kementerian Hukum dan Hak Asasi Manusia.

\section{PERATURAN PRESIDEN REPUBLIK INDONESIA BIDANG PATEN :}

- Peraturan Presiden

Republik Indonesia No. 76 Tahun $2012 \quad$ Tentang Pelaksanaan Paten Oleh Pemerintah Terhadap Obat Antiviral dan

Antiretroviral.

Jadi, berbicara mengenai UU tentang paten diatas bahwasanya memang setiap paten mempunyai sebuah peraturan tersendiri yang mendukung demi menjunjung tinggi hak dan kepemilikan dari seseorang pemegang paten itu sendiri.

Seperti diketahui bahwa paten sangat berkorelasi dengan ketersediaan banyak lapangan kerja. Negara yang menghasilkan banyak paten akan memberikan kesempatan kerja yang luas bagi penduduknya, karena salah satu syarat sebuah paten adalah dapat diterapkan dalam industri.

Aturan-aturan tersebut pada dasarnya wajib dan harus untuk diikuti dan diterapkan oleh seluruh pemegang paten di dunia. Selain untuk melindungi suatu hak kepemilikan dari masing-masing pemegang hak paten tersebut, peraturan perundang-undangan juga dibuat agar suatu hak paten dapat diperhitungkan secara jelas dan ada sanksi tersendiri bagi pelanggar.

Kembali lagi membahas mengenai Samsung, saat ini, SAMSUNG sudah memegang rate tertinggi sebagai perusahaan penyedia barang elektronik atau teknologi yang patut diperhitungkan di segi perbisnisan di dunia. Itu sebabnya, banyak teknologiteknologi yang baru berusaha mengikuti atau membuat sesuatu teknologi yang menyerupai produk-produk samsung ini. Hal ini tentu saja karena nama besar produk samsung mobile yang sudah sangat spektakuler sehingga menarik minat para pencipta produk baru untuk mengambil sedikit cuplikan mengenai produk ini. 


\section{CONCLUSION}

Kesimpulan dari artikel ini adalah, Paten adalah sebuah hak yang mengatur mengenai kepemilikan suatu penemuan atau produk yang dibuat oleh seseorang atau lebih yang ditujukan untuk menciptakan suatu produk yang dengan tujuan agar dapat bersaing dalam dunia perbisnisan dalam bidang apapun itu khususnya dalam bidang teknologi.

Contohnya SAMSUNG, kini saya kaitkan dengan Lee Byung chull, sebuah nama besar keturunan dari keluarga kaya raya yang berkebangsaan Korea yang dikenal sebagai pemegang paten dari sebuah perusahaan terkenal yang bernama SAMSUNG GRUP.

Berbicara mengenai UU tentang paten diatas bahwasanya memang setiap paten mempunyai sebuah peraturan tersendiri yang mendukung demi menjunjung tinggi hak dan kepemilikan dari seseorang pemegang paten itu sendiri.

Aturan-aturan tersebut pada dasarnya wajib dan harus untuk diikuti dan diterapkan oleh seluruh pemegang paten di dunia. Selain untuk melindungi suatu hak kepemilikan dari masing-masing pemegang hak paten tersebut, peraturan perundang-undangan juga dibuat agar suatu hak paten dapat diperhitungkan secara jelas dan ada sanksi tersendiri bagi pelanggar.

\section{DISCUSSION}

- Apa itu paten?

Sudah dijelaskan bahwa definidi hak pateen adalah sebuah hak yang mengatur mengenai kepemilikan suatu penemuan atau produk yang dibuat oleh seseorang atau lebih yang ditujukan untuk menciptakan suatu produk yang dengan tujuan agar dapat bersaing dalam dunia perbisnisan dalam bidang apapun itu khususnya dalam bidang teknologi.

- Mengapa harus mengetahui tentang paten?

Karena, pada dasarnya, kita sebagai generasi modern khusunya pengguna dunia sosialita seperti halnya teknologi, tidak mengetahui secara rinci apa saja yang ada dibelakang teknologi yang kita konsumsi tersebut. Padahal, tentu saja banyak yang dapat kita petik dengan mengetahui hal tersebut secara langsung.

- Apa yang menarik sehingga penulis mengambil judul mengenai produk samsung mobile?

Karena, subyek dibalik layar dari produk ini yang sangat menarik. Yaitu seorang yang sangat besar, seseorang yang sangat ulet dalam menjalani suatu hal, seorang yang sangat bisa dicontoh keuletannya dibidang bekerja keras, LEE BYUNG CHULL, mengawali kisahnya dalam dunia perbisnisan dengan menjual sayur dan buah, berkat jerih keringatnya kini ia adalah 
seseorang pembisnis kaya raya yang patut diperhitungkan walaupun dirinya sudah wafat.

Jadi menurut saya, study kasus yang berjudul Definisi Hak Paten Dan Penerapan Paten Pada Study Kasus Samsung Mobile ini sangat berguna untuk untuk secara langsung mengetahu apa saja tujuan baik dan sangat berguna yang ada didalamnya. Untuk itu penulis ucapkan terimakasih yang sebesar-besarnya.

\section{E. REFERENCE}

[1] O. M. Febriani and A. S. Putra, "Sistem Informasi Monitoring Inventori Barang Pada Balai Riset Standardisasi Industri Bandar Lampung," J. Inform., vol. 13, no. 1, pp. 90-98, 2014.

[2] A. S. Putra, "Paperplain: Execution Fundamental Create Application With Borland Delphi 7.0 University Of Mitra Indonesia," 2018.

[3] A. S. Putra, "2018 Artikel Struktur Data, Audit Dan Jaringan Komputer," 2018.

[4] A. S. Putra, "ALIAS MANAGER USED IN DATABASE DESKTOP STUDI CASE DB DEMOS."

A. S. Putra, "COMPREHENSIVE SET OF PROFESSIONAL FOR DISTRIBUTE COMPUTING."

[6] A. S. Putra, "DATA ORIENTED RECOGNITION IN BORLAND DELPHI 7.0."

[7] A. S. Putra, "EMBARCADERO
DELPHI XE 2 IN GPUPOWERED FIREMONKEY APPLICATION."

[8] A. S. Putra, "HAK ATAS KEKAYAAN INTELEKTUAL DALAM DUNIA TEKNOLOGY BERBASIS REVOLUSI INDUSTRI 4.0."

[9] A. S. Putra, "IMPLEMENTASI PERATURAN PERUNDANGAN UU. NO 31 TAHUN 2000 TENTANG DESAIN INDUSTRI BERBASIS INFORMATION TECHNOLOGY."

[10] A. S. Putra, "IMPLEMENTATION OF PARADOX DBASE."

[11] A. S. Putra, "IMPLEMENTATION OF TRADE SECRET CASE STUDY SAMSUNG MOBILE PHONE."

[12] A. S. Putra, "IMPLEMENTATION

PATENT FOR APPLICATION WEB BASED CASE STUDI WWW. PUBLIKLAMPUNG. COM."

[13] A. S. Putra, "IMPLEMENTATION SYSTEM FIRST TO INVENT IN DIGITALLY INDUSTRY."

[14] A. S. Putra, "MANUAL REPORT \& INTEGRATED DEVELOPMENT

ENVIRONMENT BORLAND DELPHI 7.0."

[15] A. S. Putra, "PATENT AS RELEVAN SUPPORT RESEARCH."

[16] A. S. Putra, "PATENT FOR RESEARCH STUDY CASE OF APPLE. Inc."

[17] A. S. Putra, "PATENT 
PROTECTION

FOR APPLICATION INVENT."

A. S. Putra, "QUICK REPORT IN PROPERTY PROGRAMMING."

[19] A. S. Putra, "REVIEW CIRCUIT LAYOUT COMPONENT

REQUIREMENT ON ASUS NOTEBOOK."

[20] A. S. Putra, "REVIEW TRADEMARK PATENT FOR INDUSTRIAL TECHNOLOGY BASED 4.0."

[21] A. S. Putra, "TOOLBAR COMPONENT PALLETTE IN OBJECT ORIENTED PROGRAMMING."

[22] A. S. Putra, "WORKING DIRECTORY SET FOR PARADOX 7."

[23] A. S. Putra, "ZQUERY CONNECTION

IMPLEMENTED

PROGRAMMING

STUDI CASE PT. BANK BCA Tbk."

[24] A. S. Putra, D. R. Aryanti, and I. Hartati, "Metode SAW (Simple Additive Weighting) sebagai Sistem Pendukung Keputusan Guru Berprestasi (Studi Kasus: SMK Global Surya)," in Prosiding Seminar Nasional Darmajaya, 2018, vol. 1, no. 1, pp. 85-97.

[25] A. S. Putra and O. M. Febriani, "Knowledge Management Online Application in PDAM Lampung Province," in Prosiding International conference on Information Technology and Business (ICITB), 2018, pp. 181-187.

[26] A. S. Putra, O. M. Febriani, and B. Bachry, "Implementasi
Genetic Fuzzy System Untuk Mengidentifikasi Hasil Curian Kendaraan Bermotor Di Polda Lampung," SIMADA (Jurnal Sist. Inf. dan Manaj. Basis Data), vol. 1, no. 1, pp. 21-30, 2018.

[27] A. S. Putra, H. Sukri, and K. Zuhri, "Sistem Monitoring Realtime Jaringan Irigasi Desa (JIDES) Dengan Konsep Jaringan Sensor Nirkabel," IJEIS (Indonesian J. Electron. Instrum. Syst., vol. 8, no. 2, pp. 221-232.

[28] D. P. Sari, O. M. Febriani, and A. S. Putra, "Perancangan Sistem Informasi SDM Berprestasi pada SD Global Surya," in Prosiding Seminar Nasional Darmajaya, 2018, vol. 1, no. 1, pp. 289-294. 